\title{
A ciliary timer for S-phase entry
}

William J. Snell* and Erica A. Golemis ${ }^{\ddagger}$

In the Opinion article 'What's taking so long? S-phase entry from quiescence versus proliferation', Hilary Coller proposes that CDC6 stabilization, relocalization and loading onto chromatin cause a delay in the exit of cells from quiescence ${ }^{1}$. As a complement to this, we wish to highlight evidence that ciliary shortening and release of the centriole from its basal-body role to its role in the centrosome contribute to the delay. Such a role for the centriole is in accord with a 1979 report by Tucker, Pardee (the same Pardee who, as noted by Coller, first argued for the existence of a quiescent state) and Fujiwara ${ }^{2}$; these authors showed that treatment of ciliated, quiescent cells with platelet-derived growth factor (PDGF) and other serum factors induced rapid ciliary shortening. Tucker et al. also demonstrated that only cells that had completely resorbed their primary cilium (thereby releasing the captive centriole) became competent to enter $\mathrm{S}$ phase. The authors proposed that "Certain centriole events may therefore be necessary before DNA synthesis can be initiated in 3T3 cells."

In most normally cycling cells, the centrosome (which comprises pericentriolar material and two centrioles) is a microtubule-organizing centre and hub for the assembly of signalling complexes during the S, G2 and M phases of the cell cycle. However, in post-mitotic cells (early G1 phase) and in cells that are driven to quiescence, one of the centrioles within the centrosome becomes firmly attached to the cell membrane, where it differentiates into the basal body of the primary cilium ${ }^{3}$. Over the past few years, a flood of studies have emphasized that most mammalian cells have a primary cilium ${ }^{4}$, which is in a complex relationship with the cell cycle ${ }^{5}$. Furthermore, the important roles of ciliumgenerated signalling have been documented in the Hedgehog and PDGF $\alpha$ pathways ${ }^{6}$, both of which are important for triggering the renewed proliferation of quiescent cells. In 2007, Pugacheva et al. ${ }^{7}$ confirmed that shortening and resorption of cilia were hallmarks of the passage of initially quiescent cells into and through S phase, and identified an unexpected role for the Aurora-A kinase as a molecular inducer for the process.

Coupled with these observations is a growing number of studies that demonstrate an essential role for an intact centrosome in allowing S-phase entry in normally cycling cells. Sluder ${ }^{8}$ and others have documented that cells with ablated centrosomes are unable to progress from G1 to S phase. Matsumoto and Maller ${ }^{9}$ demonstrated that cyclin E contains a centrosome-localization signal, and disruption of cyclin E binding to the centrosome is required for S-phase entry. These and other studies discussed by Sluder ${ }^{8}$ indicate that centrosome-initiated signals are necessary for actively cycling cells to enter G1. Thus, as cells emerge from quiescence and resorb their cilium as part of the cilium-centriole-centrosome cycle ${ }^{10}$, the concomitant modifications of the centriole and centrosome are proposed to generate 'cell-cycle ready' signals ${ }^{11}$. These signals are necessary to activate CDK2-cyclin E signals and allay p53 checkpoints and, together with the nuclear events summarized by Coller, contribute to the timing of cell cycle re-entry.

William J. Snell is at the Department of Cell Biology,
University of Texas Southwestern Medical Center,
5323 Harry Hines Boulevard, Dallas, Texas
75390-9039, USA.
Erica A. Colemis is at the Fox Chase Cancer Center,
333 Cottman Avenue, Philadelphia, Pennsylvania
19111, USA.
e-mails: william.snell@utsouthwestern.edu;
ea golemis@fcc.edu
doi:10.1038/nrm2223-c1

Coller, H. A. What's taking so long? S-phase entry from quiescence versus proliferation. Nature Rev. Mol. Cell Biol. 8, 667-670 (2007).

2. Tucker, R. W., Pardee, A. B. \& Fujiwara, K. Centriole ciliation is related to quiescence and DNA synthesis in 3 T3 cells. Cell 17, 527-535 (1979).

3. Sorokin, S. Centrioles and the formation of rudimentary cilia by fibroblasts and smooth muscle cells. J. Cell Biol. 15, 363-377 (1962).

4. Rosenbaum, J. L. \& Witman, G. B. Intraflagellar transport. Nature Rev. Mol. Cell Biol. 3, 813-825 (2002).

5. Quarmby, L. M. \& Parker, J. D. Cilia and the cell cycle? J. Cell Biol. 169, 707-710 (2005)

6. Singla, V. \& Reiter, J. F. The primary cilium as the cell's antenna: signaling at a sensory organelle. Science 313, 629-633 (2006).

7. Pugacheva, E. N., Jablonski, S. A., Hartman, T. R., Henske, E. P. \& Golemis, E. A. HEF1-dependent Aurora A activation induces disassembly of the primary cilium. Cell 129, 1351-1363 (2007).

8. Sluder, G. Two-way traffic: centrosomes and the cell cycle. Nature Rev. Mol. Cell Biol. 6, 743-748 (2005). Matsumoto, Y. \& Maller, J. L. A centrosomal localization signal in cyclin $\mathrm{E}$ required for $\mathrm{Cdk} 2$ independent S-phase entry. Science 306, 885-888 (2004).

10. Pan, J. \& Snell, W. The primary cilium: keeper of the key to cell division. Cell 129, 1255-1257 (2007).

11. Qin, H., Wang, Z., Diener, D. \& Rosenbaum, J. Intraflagellar transport protein 27 is a small G protein involved in cell-cycle control. Curr. Biol. 17, 193-202 (2007). 